\title{
Friends, Neighbours and Distant Partners: Extending or Decentring Family Relationships?
}

by Lynn Jamieson, David Morgan, Graham Crow and Graham Allan
University of Edinburgh; University of Southampton; University of Keele

Sociological Research Online, Volume 11, Issue 3,
<http://www.socresonline.org.uk/11/3/jamieson.html>.

Received:21 Aug 2006 Accepted: 27 Sep 2006 Published: 30 Sep 2006

\section{Introduction}

1.1 There is a longstanding recognition that grasping the meaning and significance of any specific personal relationship requires an understanding of the whole constellation of personal ties within which people are embedded. So for example, to understand kinship it is equally necessary to understand friendship (Allan, 1979). This special collection brings together research which offers insight into personal relationships of working-age adults beyond or outside of the conventional domestic context of a co-resident couple with or without children. In comparison to the wealth of research on couple and parent-child relationships, other adult personal relationships are relatively under-researched and it is hoped that this issue will encourage further work. Examples of the kinds of relationships considered here include sexual relationships and partnerships between adults outside the family-based household (Holmes, Roseneil, Reynolds), the friendships of those not living with a partner (Budgeon), the whole constellation of personal relationships of single women (Simpson) and their negotiation of the identity 'single woman' (MacVarish), .neighbours (Boyce, Stokoe), and relations with paid carers who enter into family contexts (Pockney).

1.2 These relationships are all outside the established package of partnership, parenthood and household although all represent some aspects of intimacy: bodily, emotional and privileged knowledge of the other person. They have some affinities and overlaps with family practices while also having their own distinct characteristics. The detailed exploration of these different sets of practices, using a variety of methodologies, may help us understand their particular logics and rationales, as well as how they are distinct from or have continuities with more regularly understood relationships of family and kinship. These individual studies can also remind us of the significance and sources of the inequalities and external structural factors surrounding and shaping these relationships and limiting the degrees of freedom enjoyed by individuals.

1.3 Having a more complete picture of the whole constellation of personal relationships is urgently needed to inform contested interpretations of social trends in personal life. One particular line of interpretation of social change is that some of the non-familial relationships discussed in this collection are eclipsing familial relationships in their significance. In a review of research across personal relationships at the end of the twentieth century, Jamieson $(1998,1999)$ noted that although friendship was claimed theoretically as the ideal intimate relationship, the couple remained the popular choice at the centre of adult personal life. However, at the time of this collection, a growing number of researchers, including contributors to this issue, suggest the growing importance of adult friendships (Pahl and Spencer, 2004, Spencer and Pahl 2006) and believe they are seeing the focus of personal life shift from the couple, and particularly the gendered, heterosexual, co-resident, family-founding couple, to a more fluid network of intimates including friends, lovers and neighbours (Budgeon, this volume; Roseneil, this volume; Roseneil and Budgeon, 2004, Savage, Bagnall \& Longhurst, 2005). The suggestion is that this more fluid network may be taking over, practically and emotionally, as the important relationships in people's lives and undermining the cultural dominance of conventional family relationships as the idealized relationships to which we aspire. A number of contributions in this volume add to a body of recent research which suggests that the boundary between 'familial' and 'non-familial' relationships is increasingly blurred in everyday lives. One way of portraying this is in terms of the elasticity and constant stretching of the boundary of what constitutes 'family' as the constellations that people designated as 'familial' become increasingly diverse. Another way of portraying this is to say that the idea and ideal of family is losing ground to different understandings of how life should be lived. These different ways of interpreting the same trends disagree about how fundamental a shift in actual practices has taken place. 


\section{Contested Change and Continuity}

2.1 That there have been major changes in the context of personal life and in key aspects of how personal life is conducted is not at issue. It is an uncontestable fact, for example, that, relative to the middle of the twentieth century, a growing proportion of adults across much of the rich 'western' world spend at least some of the years conventionally associated with the co-resident couple outside of that particular arrangement. There have been sufficiently dramatic demographic changes since the middle of the twentieth century for demographers to talk of a 'second demographic transition' (Lesthaeghe 1998, 2004). Changes in Britain in patterns of parenting (the decline in women having more than two children, the increase in the average age at which women have their first child, increased childlessness, the increase in the proportion of births outside of marriage), partnering (delayed marriage, increased cohabitation, higher rates of dissolution, and higher rates of 'solo living'), and in gender divisions of labour (increase in women combining paid work and caring and the demise of the male breadwinner model ideal) are well documented.

2.2 However, what is at stake is how to interpret the significance of this constellation of change and its implications in terms of the future trajectory of personal life. The more pessimistic commentators read changes as people turning their back on the family and the corrosion of society and character by an increase in selfish individualism focused on no-responsibilities life styles. Academic accounts that are trying to explain the detail of demographic trends are usually much more circumspect but there are also many broad sweep academic accounts that essentially support elements of this negative interpretation of events. These darker assessments include the stress on risk and individualization in the works by Beck (1992) and Beck-Gernsheim $(1995,2001)$ and the analysis of liquidity in several works by Bauman (2000, 2003). On the other hand the same events can be interpreted optimistically as a democratization of personal life, as in Giddens' widely-cited and debated book, The Transformation of Intimacy.

2.3 These influential discussions of family and intimate life agree that changes of a fundamental nature have been taking place. We might also add Castells's $(1996,1997)$ discussion of the erosion of patriarchalism or Calhoun's (1991) discussion of shifting balance between direct and mediated relationships to this list of theorists indicating fundamental change in personal life. There are considerable differences between these writers and we would not wish to impose an artificial uniformity on to these theoretical accounts. What they have in common, if anything, exists at a high level of generality. However, when any detail concerning the mechanisms of change in personal life are provided, and in some cases it is not, the following elements occur in different combinations and with different emphases, providing some sense of resemblance between these theories. These include transformation in the relationships between men and women, for some undermining the foundations of patriarchy, the weakening of the obligations and duties associated with family, kinship and generational ties, an elaborated understanding of sexuality and greater tolerance of many forms of sexual expression and a stress on individual decision making and responsibility as the driver of personal life. In various ways (and again, with different emphases) these transformations in intimacies are linked to other changes in 'western' societies which some authors would bundle into the concept of 'globalization', in the re-organization of paid employment, extension of education, changes in leisure, consumption, mobility and information technology, and in the ways in which the state engages with or disengages from personal life. Differences between various accounts may be described in terms of the degree of emphasis on individual agency as well as the extent to which these changes are seen as positive or negative.

2.4 Critical discussions of these various accounts which seek to explain change in personal life have taken various tacks. One focus is on questioning whether the transformations have been as deep and as farreaching as it seems to be being claimed. The case of change in gender relations has been particularly contested and many studies find women continuing to do much of the work of caring and kin-keeping. A number of empirical studies have sought to demonstrate the continued importance of families. For example, North American researchers have used a large longitudinal study to demonstrate continuity in processes of socialization and inter-generational transmission despite new family forms (Bengtson et al, 2002) and smaller scale qualitative research to show how families succeed in this work by being 'not so nuclear', drawing on wider familial and non-familal relationships 'in the context of a cultural belief in the independence of nuclear families' (Hansen, 2005). If families are doing the same business in different conditions it is not clear whether the sense of a radical break with the past can be sustained. It may be, rather, that a change of form masks continuity of function. Another line of critique has argued that differences in terms of social class, region and ethnicity are ignored or played down in the broad sweep accounts. These debates clearly form part of the background inspiring the particular studies presented in this edition. This is not to say that the contributors all support one or more of these interpretations of the changes that are taking place but the kinds of themes raised by these influential ideas, about the impact of wider, sometimes global, changes on personal lives, certainly find their way into many of the studies. Thus, to give one simple example, the innovative practices described in Mary Holmes' study of relationships at a distance can be seen, in part, as a response to new ways of organising work, careers and travel and her study is appropriately contextualized by reference to debate about such changes.

2.5 To what extent do the contributions in this collection suggest that we are seeing a decentering of the family rather than simply an extension of family practices? In order to answer this we need to ask a prior question, namely one concerned with the novelty or otherwise of key processes. For example does the blurring of the distinctions between family and non-family represent a new departure? When considering such a question of historical change we need to be clear about the kind of time frame that we are considering. Thus the idea of a blurring of the boundaries between family and non-family might not seem all that strange in eighteenth-century England where there was often considerable overlap between ideas of family, servants, friends and acquaintances (Tadmor, 2001). It is likely that when people (sociologists and their research subjects) talk of change they are taking a much narrower temporal frame of reference and the comparison may be made with a model of the family life-course running roughly from the late nineteenth-century to the 1950s or, in more popular understandings, in terms of generations such as 'my 
parents' generation, my grandparents' generation' and so on. In terms of these kinds of comparisons it is possible to identify several important changes in family and intimate practices as well as in attitudes and values. Whether, however, all this adds up to an increased blurring of the boundaries between family and non-family remains more open to question.

2.6 The first thing that can be said is that many of the people, whose voices are heard in the individual studies presented here, feel that they are dealing with novel situations and that they are responding in imaginative and innovative ways. Some indeed manifest a sense of being pioneers in sexual and intimate relations and these claims are reflected in the writings of some, but by no means all, of the researchers whose work we include or cite. This is found, to some extent, in Holmes' study of long distance relationships and, especially in Roseneil's accounts of not living with a partner. A similar sense of novelty is partially found in Macvarick's discussion of the "new single woman". Of course a sense of change and innovation is not necessarily the same as deeper, underlying and more long-lasting structural or institutional changes. But nevertheless, even a sense that we are engaging in something distinctive and new is of significance in its own right as well as possibly actually bringing about the changes claimed. However, it is equally possible to find evidence of continuity in the studies presented in this issue. Stokoe's study of neighbourhood relationships suggests clear distinctions between the 'public intimacy' that characterizes such relationships and the private intimacies of family living. The stress on distance between neighbours can be seen as reinforcing familial boundaries. Pockney's study of relationships between paid carers and people with learning disabilities shows a certain lack of reciprocity in how the relationship is understood, with the latter sometimes mistaking 'friendliness' for ' friendship'. There would appear to be some resistance on the part of carers to an erosion of the boundaries between paid carers and their clients.

2.7 Nevertheless, we are able to point to a range of intimate and personal relationships which are important to individuals in all kinds of ways and which lie at some distance from what is conventionally understood as "family". To return to our original question, do these represent an extension of family practices or do they point to a de-centering of family life in the sense that they constitute genuinely alternative points of reference and may be seen as being at least as important as blood relations? The studies presented in this volume do not provide a conclusive answer to this question. There is certainly evidence for an extension of family relationships in terms of the language used so that individuals and practices may be described as being "like family" where it is clear that this is a positive evaluation. It is also evident from some of our studies that these non-familial intimate relations provide practical and emotional support for particular family members in such a way as to enable particular clusters of family relationships and practices to continue. It may be the case that the limited intimacies that take place between paid carers and clients in Pockney's study assist in the maintenance of familial ties and something similar may be suggested for the friends and neighbours analysed in Boyce's study of a working-class housing estate. What is being suggested here is that, in the absence of particular extra-familial intimate practices, family relationships (couples, parents and children, kin) might not be able to continue as they had done before.

2.8 On the other hand, it would be misleading to see the relationships and practices described here as simply constituting extensions of or functional alternatives for family relationships. For one thing, it is clear that some of the individuals quoted in articles in this issue do not see it in these terms. While explicit rejections of the family ideal might be rare (but not absent) it is evident that many of the individuals concerned see these relationships as valuable in their own terms without reference to wider notions of family. In some cases there may be a more or less explicit endorsement of the values of individualization, such as notions of personal fulfillment and identity, as somewhat outside of the familial domain. Even where this is not the case, the relationships may be understood in terms that confirm that these practices are not the same as, or even like, family. A possible example here are the studies of neighbours and neighbourliness where the practices and the values of distance and privacy are not the same as the kinds of practices associated with close family. Something similar may often be said in relation to friendship although here the boundaries may be less marked. However, care has to be taken not to exaggerate differences between family relationships and other personal relationships by neglecting the complexities of how people 'do' intimacy. Some boundary work creating distance sometimes occurs even within family households and the intimacies of the household are typically only selectively extended to wider kin who are sometimes also called 'family'. The practices of neighbouring and friendship may involve similar internal boundary work, for example, distinguishing best friends from those beyond the inner circle.

\section{Theoretical Issues and Methodological Tools in the Analysis of Change in Personal Life}

3.1 There are a number of theoretical and methodological issues that we think need to be taken further in order to get additional purchase on themes of social change to which all of these articles speak. Understanding the nature of social change is a complex matter and we wish to consider the tools that might assist with the careful, empirically based research which is necessary in order to explore these issues thoroughly.

3.2 The first theoretical issue we wish to revisit is that of the relationship between public discourse and private values, subjectivities and practices. A range of contemporary theorists (e.g. Rose, 1996, Smith, 1999, Butler 1997) have reworked the claim much elaborated by Michel Foucault that selves, including bodies, emotions and states of minds, are 'produced' or 'constituted' by discourse. Personal relationships are given a relatively minor part by some theorists in this self-engaged process of 'production' and in some psychoanalytically informed approaches the focus is typically fairly exclusively on parent-child relationships. Traditions which draw more explicitly on symbolic interactionism and phenomenology tend to give personal relationships a more leading role, emphasizing the potency of emotionally charged interactions with 'significant others' across the life course for ideals, subjectivities and practices. These are not differences we can explore further here but we note that researchers of families and relationships need to attend theoretically to the extent to which and ways in which personal relationships and public discourse 
3.3 In the1980s Barrett and McIntosh talked of the persistence of familial ideology idealizing 'the family' of co-resident husband earner/provider, housekeeping, child caring wife and children and familism. In their view this shaped the organisation of society around the assumption that 'the family' is the basic unit of society despite the reality of a whole array of family types, rising divorce, rising cohabitation, the marked increase of married women with children in the labour force, and the onslaught of feminist and radical critiques of the family (Barrett and McIntosh 1982, Morgan, 1985). In the 1990s authors, particularly in North America, described nostalgia in popular culture for a mythical past in which people lived in conventional stable happy families as a response to change and uncertainty (Coontz, 1992; Skolnich, 1991). Discussions of family life often acknowledge a gap between ideals and practice. For example, in analysis of post-divorce families Smart (2005) works with the contrast made by Gillis between 'the families we live by' and the 'families we live with', the former being shaped by a variety of historically located discourses that are woven into everyday family practices (Gillis, 1997). Gross (2005) argues that the image of life-long marriage, which many commentators believe has lost ground, is in fact still hegemonic and informing private ideals, a 'meaning-constitutive tradition'.

3.4 All of the editors have both contributed to and analysed public discussions about private lives. Morgan $(1985,1991,1992,1996)$ has analysed how changes in family and marriage across the twentieth century came to be characterised as a shift 'from institution to relationship' with an implied shift from traditional and public obligations to private pleasures and values. Jamieson has analysed the constructions of 'the modern family' (1987) and the shift in focus from 'the family' to the 'good relationship' as the site of intimacy associated with historically specific idea that intimacy is at the centre of meaningful life (1998). Allan and Crow (1989) have discussed historical shifts in representations of the home and community. Crow has also explored shifts in the way in which personal relationships have been presented as forms of social solidarity (2002). Allan with his co-editors consider continuity and change in 'affairs' as an institution that relies on a gap between the ideals and practices of relationships (Duncombe et al 2004). While none would definitively claim to capture the theoretical nature of the relationship between public stories and lives as they are lived, in each case this relationship was problematised. For example, Morgan noted the association between the social representation of personal life as privatised intimacy centred on 'relationship' and the emergence of 'psy' experts claiming specialist expertise in treating 'relationships'. Jamieson argued that the neither the notion of 'the modern family' of the 1970s nor the 'intimacy' in popular and academic commentaries of the 1990s summed up the complex ties of lives as they were lived.

3.5 Those claiming that the idea and ideal of family is losing ground sometimes point to cultural products celebrating friendship and more unconventional relationships (Plummer, 2003, Weeks et al. 2001) suggesting an overall shift in public rhetoric. Even if the discourse of friendship is in the ascendancy, political and commercial uses of images of conventional families certainly remain part of the backdrop of everyday lives. There has been no significant attempt to measure the overall balance of 'friends' and 'family' in popular discourse over time. But it would never be sufficient to mechanically achieve this, say by charting broadcast time given to friends versus family. Further work needs to be done choosing between the range of possible ways of theorising the relationships between public discourse, private ideals, subjectivities and practices and to separate out the friends we live by, values and constructions of friendship, from the friends we live with, the actual ways in which people 'do' friendship.

3.6 One concept that seems to us to be worthy of further development in the work of unpacking the contested relationship between public discourse and private ideals, subjectivities and practice and helping to specify their articulations empirically is Morgan's use of 'family practices'. It is possible that this concept can be adapted to the relationships described in this volume and some of the authors have taken steps in this direction. With respect to familial relationships, sociological researchers no longer presume a definition of 'the family' but seek to discover what 'family' means to research participants. It is generally recognized that this cannot be done adequately by simply asking what people think but, following Morgan (2002), by exploring 'family practices' and how people 'do family'. Morgan's use of the concept 'practices' acknowledges an articulation between ideals and practices. He suggests that the routine ways in which people's actions create some activities, spaces and times as 'family' are the stuff of this articulation. Similarly it is possible to explore how people 'do' other kinds of intimate relationships, for example practices of friendship' and more general 'practices of intimacy'. A number of contributions in this volume move in this direction by analysing practices of friendship, neighbouring and caring relationships.

3.7 Much about the relationship between public discourse and private lives remains under-theorized, including the factors enabling or delimiting the extent and nature of their divergence and the possibilities for resisting, refashioning and creating public discourse in private lives. Academic discussion of social change in personal life offers contested accounts of the nature of the gap between discourse and practice. For example, Jamieson $(1998,1999)$ suggested that the constellation of ideals and intimate practices that Giddens referred to as the 'pure relationship,' is more pervasive as a discourse at the level of popular culture than as an organizing principle of lived practice. Moreover, even within popular culture, it may not be the dominant discourse; consistent with Connell's account of hegemonic masculinity, stories of heterosex celebrating dominant-man and submissive-woman remain a strong strand of popular culture. However, a number of the studies in this issue report the views of groups of women which certainly do not fit the latter analysis and may not fit the former (Budgeon, Rosneil, Reynolds and Simpson). General claims about messages concerning personal life circulating in popular discourses and their take up in everyday lives often involve a degree of extrapolation beyond the evidence. Assembling and analyzing data about popular discourse as well as personal practice is more than the tasks undertaken by a typical qualitative research project. Among the papers in this issue, only Stokoe combines analysis of participants' talk with analysis of television and radio broadcast on the same theme. But also, as already noted, with the exception of Morgan's concept of 'family practices', few theoretical tools for addressing this articulation have been adopted by researchers studying personal relationships. 
3.8 The second theoretical issue we wish to discuss concerns the appropriate theoretical acknowledgement of socially structured constraints and disadvantage. Irwin (2004, Irwin and Bottero 2000) is one of a number of authors who have taken issue with the presumption that the current emphasis on choice in public discourse and in the accounts of social change produced by theorists such as Bauman, 1995, Beck, 1992 and Giddens, 1991, entails the 'loosening' of choices and values from structural processes. 'Subjectivities are not more autonomous of the social interaction order than in the past, but remain an integral part of that order, even in a time of rapid change' (Irwin, 2004, paragraphs 1.2 \& 1.8 ). This is a concern we share. We must also acknowledge that one possible criticism of an approach to analysis of personal relationships which emphasises 'doing the relationship' through a range of practices is that it may play down some of the substantial constraints, material and ideological, that confront attempts to shape personal and intimate lives. Opportunities for intimate practices may be more numerous and more accessible than they once were historically but this does not necessarily mean that they are evenly distributed in the present.

3.9 However, it has proved very difficult in the confines of small scale research projects to unpack the relationship between lives as they are lived and the opportunities and constraints of wider contexts. Such contexts include material circumstances and social capital as well as cultural discourses about personal life. In this collection we bring together a range of papers focusing on structurally different types of relationships - paid carer, neighbour, friend and partner. The individual studies included here pay varying degrees of attention to external structural factors. A number directly document the practices of a disadvantaged and stigmatized group (Boyce, Stokoe). Among the studies of single women, only Simpson clearly concludes that their options are still shaped by material and cultural constraints they face as single women. However, reading across the articles also reminds us of the differential significance and sources of the inequalities and external structural factors surrounding and shaping different types of relationships and limiting the degrees of freedom enjoyed by individuals. For example, it is only in a rather limited sense that we can be said to 'choose' our neighbours and the idea of friends as 'freely chosen' may be found to be limited in practice for those who are dependent on paid carers for much of their personal social interaction (Pockney, this volume).

3.10 The final theoretical issue we wish to discuss is the utility of the concept of life course. Conventionally, the life-course (and especially the earlier idea of the 'life-cycle') was focused on changing familial relationships with particular emphasis upon household changes over time. However, the idea need not be restricted in this way and it can be extended to include or explore the other kinds of relationships under consideration here. Whether the concept remains of value is a question that has not yet been fully addressed by research across this wider set of personal relationships. We would argue that in researching personal life it remains important to attend to people's sense of staging their life over time and of generational change. As the article by Simpson begins to suggest, those who never partner or parent do not lead lives without any sense of milestones or markers. The contributions discussing single women (Budgeon, Reynolds, Roseneil and Simpson) do not all explicitly address the extent to which they see themselves as having broken with the trials of single women of previous generations or as a pioneering generation but suggest slightly contradictory accounts, reflecting their different samples and approaches. Ideas of generation and inter-generational relationships that are crucial to the understanding of family practices (and may well be increasing in importance as partnerships become more fragile) may be of more limited importance in understanding the kinds of relationships being discussed in this present collection. Nevertheless generationally located experiences may inform and shape the practices we are exploring here. For example, while cohabiting with a heterosexual partner without marriage moved from pioneer status to convention between the generations coming of age in the early 1960 s and the 1990 s, so it may be that living alone or living apart together are becoming more conventional options for more recent generations.

3.11 Further, it is likely that our relationships take on different significances and characteristics at different 'stages' of the life course because the constraints and opportunities of the contexts in which we are embedded shift with life course stage. While media representations of friendship, for example, tend to concentrate upon the young and unattached, it is also the case that friendship can take on particular significance for the elderly (Phillipson, et al 2001, Wenger 2001). Similarly, neighbours may be particularly important to parents (including lone parents) with dependent children (Boyce, this volume). At the same time particular sets of friends continue or change during individual life-courses and it is likely that ideas of the nature and significance of friendship also undergo changes within these periods. Further, we need to remember that life course also refers to the interaction of biographical and historical changes and that all kinds of intimate relationships (and not just family relationships) have been shaped by public shifts in attitudes and practices around gender and sexuality as well as by actual legislation.

3.12 The life course stages of early childhood and older age are likely to remain relevant categories of social analysis. Personal capacities and opportunities for practices of intimacy are radically modified by the social arrangements and conventions which seek to manage the biological processes of growing and ageing at the beginning and end of life. In early childhood there are limited possibilities of constructing nonfamilial relationships and for initiating many aspects of intimacy. Association with others outside of the family household is typically mediated by one or more custodial parent. But also in the early years, physical and emotional development, social skills and forms of communication are still being learned. Once placed in age-graded institutions like nurseries and schools, association with multiple others is enforced rather than chosen. By school age children are typically preoccupied with sustaining a social world with a sense of choosing and being chosen in friendship (Borland et al, 1998, Dunn, 2004). At the same time, the possibility of making and keeping friends can be constantly disrupted by institutional practices and parental decisions. In older age, physical mobility and hearing may be impaired and some choose or feel forced to move to residential settings that are exclusively for older people. Such a move may provide new opportunities for association but also disrupt pre-existing relationships. Possible new 
friends may not escape comparison with past long-term personal relationships, and communication can quickly create awareness of lack of shared memories and a shared view of the world (Jerrome, 1992). Also new relationships formed in settings such as supported accommodation are particularly vulnerable to disruption by illness and death.

3.13 Although all the papers have some bearing on this topic, we do not feel that we have been entirely successful in capturing the full complexities of a life-course perspective in the present collection. It is a matter of regret that there are no contributions dealing with children's relationships or with those of older people. However we would wish to acknowledge that intersections of biographical and historical time are central to the analysis of these different types of intimate relationships and that there is a need for research which features these dimensions more fully. It may well be that the idea of the life course may prove to be incomplete when considering these wider relationships and that, just as we can see a blurring of the boundaries between family and non-family, so too perhaps we see a weakening of the transitions and stages around which the notion of the life-course is constructed (Budgeon, this volume; Holdsworth and Morgan, 2006). However, we still need to remember that all kinds of relationships have their particular and linked histories. A good example here is provided by Reynolds (this volume) who describes the individualized timings and sequencings found when women talk about their relationships with men.

3.14 Finally we also want to raise some additional methodological considerations even if we do not have the space to explore these in any depth. Firstly we wish to reaffirm the value of small-scale qualitative research exemplified by the contributions. The qualitative data are gathered through a variety of methodological approaches - discourse analysis, various styles of qualitative interviews, observation and some mixed methods. Their small samples are constituted in different ways. In some cases they are studies of people in a particular place and in others of individuals with common characteristics included without reference to place. In the nature of things, there was no overall strategy in the selection of research sites and samples. They nevertheless give some sense of the range of practices of intimacy in such nonfamilial relationships as friendship and neighbouring. While it is not possible to simply add up diverse small scale studies of a particular type or types of relationship to get a bigger picture, reading across them does facilitate appropriate generalization, even if only by warding off premature conclusions through the awkwardness of apparent contradictions. .

3.15 Secondly we wish to note the possibility that more value would have been added by more mixed methods. Understanding the context in which lives are lived is always crucial to any generalization from qualitative analysis. With the exception of Roseneil, the contributions do not contextualize or complement the qualitative data with more statistical material. Mixing quantitative and qualitative methods is rapidly becoming the norm for funded research but this can be done in a range of ways (Bryman, 2006), some of which may be more productive for analysis of social change in personal life than others. Mason advocates comparative analysis that combines quantitative and qualitative methods in a 'qualitatively driven' way that is exploring 'as fully as possible the situational contours and contexts of social processes, and then making strategic and theoretically driven comparisons with similar processes in other contexts, or similar contexts where different processes occur, to generate explanations' (Mason, 2006, 16). This would typically involve larger-scale, more coordinated studies than those of the solo-researcher and the PhD student. However, something towards this may also be achieved by more astute reading across literatures and research projects by qualitative and quantitative researchers alike. More regular seeking out of relevant secondary analysis of large data sets by qualitative researchers would help locate their work. The Scottish and British Social Attitude Surveys, the General and Scottish Household Surveys, The British Household Panel Survey and their European and international equivalents have all contained some material of relevance to the study of friends, neighbours, couples living apart and people living on their own, for example. Similarly, some of the speculative interpretations of statistical patterns made by those analyzing large data sets could be improved by more regular reading by quantitative researchers of qualitative research literature.

3.16 Finally we wish to acknowledge the possibility that no study, even a mixed method, large and complex multi-disciplinary one, could fully capture the complexity of social change in human intimate life. Certainly some have debated whether there are inherent difficulties in conducting a purely sociological analysis of emotional life (Craib,1994, 1995, Jackson, 1993, Turner and Stets, 2005). Some have argued that the conventional sociological tool-box does not contain all that we need for this analysis and that we have to look beyond the discipline (to psycho-analysis or to linguistics, for example) in order to confront these complexities. It may be that there cannot be a fixed standpoint from which to study change and the notion of a fixed standpoint remains theoretically and methodologically problematic (Ramazanoglu, 2002). There are shifting boundaries, theoretically, politically and practically, between public discourse, private subjectivities and practices. The very fluidity which is at the centre of our theoretical concerns necessarily throws up everyday difficulties when it comes to explore meanings. Conventional categories such as 'single', 'partner', 'friend' and 'neighbour' may prove to be extremely variable and great care has to be taken when, for example, using the terms in questioning potential informants. None of this makes sociological studies of diverse aspects of personal life any less urgent.

\section{Conclusion}

4.1 In the introduction we contrasted the notion that the boundary of what constitutes 'family' is being constantly stretched with the notion that the idea and ideal of family is losing ground to different understandings of how life should be lived. What the articles on friendship, neighbouring, distant couple relationships and paid caring relationships in this issue suggest when choosing between these accounts is, perhaps inevitably, 'it depends'. But we can begin to identify some of the factors that with further efforts in terms of theorizing and data gathering and analysis are likely to offer additional insight. These range from a more developed theorizing of the relationship between public discourse and private practice to more systematic use of mixed methods and comparative work. In conclusion we return to the case that has 
been made for extending the concept of 'family practices' to analysis of other practices of intimacy, albeit without losing theoretical sight of transmission of structural inequalities. Cumulatively research focusing on 'practices' in this sense is beginning to establish whether and how the logic or the ethics of the practices (whether in the context of friendship, neighbouring, of living apart together or of being a paid carer), overlap with or are distinct from the logics and ethics associated with family practices. It remains important to attend to the extent to which the actors themselves define their chosen ways of life to be in opposition to or as rejecting family values and practices. It is possible that the mere fact that researchers are not only considering practices of intimacy in non-familial relationships but also considering them in relation to and in comparison with family practices itself leads to some decentering of family practices. Family practices come to be seen, as the editors have argued in different places in the past, in the context of a wider and fluid set of social relationships.

\section{References}

ALLAN, G. (1979) A Sociology of Friendship and Kinship. Allen and Unwin, London.

ALLAN, G. and Crow G. (eds) (1989)Home and Family: Creating the Domestic Sphere Macmillan, London BAUMAN (1995) Life in fragments : essays in postmodern morality Blackwell, Oxford.

BAUMAN, Z. (2000) Liquid Modernity Polity, Cambridge.

BAUMAN, Z. (2003) Liquid Love: On the Frailty of Human Bonds, Polity, Cambridge.

BARRETT, M. and McIntosh, M. (1982) The Anti-Social Family Verso, London.

BECK, U. (1992) Risk society : towards a new modernity London, Sage.

BECK, U. and Beck-Gernsheim, E. (1995) The normal chaos of love Polity, Cambridge.

BECK, U. and Beck-Gernsheim, E. (2001) Individualization : institutionalized individualism and its social and political consequences Sage, London.

BENGSTON, V., Biblarz, T., Roberts, R. (2002) How Families Still Matter: A Longitudinal Study of Youth in Two Generations Cambridge University Press.

BORLAND, M., Laybourn, A., Hill, M., Brown, J. (1998) Middle Childhood: The Perspectives of Children and Parents Jessica Kingsley, London.

BRYMAN, A. (2006) 'Integrating qualitative and quantitative research: how is it done?' Qualitative Research 6. $97-113$.

BUTLER, J. (1997) The Psychic Life of Power: Theories in Subjection Stanford University Press.

CALHOUN, C. (1991) "Imagined Communities and Indirect Relationships: Large Scale Social Integration and the Transformation of Everyday Life," in P. Bourdieu and J.S. Coleman, eds.: Social Theory for a Changing Society. Boulder, CO: Westview Press and New York: Russell Sage Foundation, 95-120.

CASTELLS, M (1996) The Rise of the Network Society Blackwell, Oxford.

CASTELLS, M (1997) The Power of Identity Blackwell, Oxford.

CRAIB I. (1995) 'Some Comments on the Sociology of Emotions' Sociology, 29, 151-158.

CRAIB, I. (1994) The Importance of Disappointment Routledge, London.

COONTZ (1992) The Way We Never Were: American Families and the Nostalgia Trip Basic Books, New York.

CROW, G. (2002) Social Solidarities Open University Press: Buckingham.

DUNCOMBE, J., Harrison, K., Allan G. and Marsden, D. (eds.) (2004) The State of Affairs: Explorations in Infidelity and Commitment, Lawrence Erlbaum Associates, Mahwah, New Jersey.

DUNN, J (2004) Children's Friendships: the beginnings of intimacy, Blackwell, Oxford

GROSS, N. (2005) 'The Detraditionalization of Intimacy Reconsidered' Social Theory 23, 286-311

GIDDENS A. (1992) The Transformation of Intimacy Polity Press, Cambridge.

GIDDENS A. (1990) Modernity and Self Identity Polity Press, Cambridge.

GIDDENS (1991) Modernity and Self-Identiy: Self and Society in the Late Modern Age Polity Press, Cambridge.

GILLIS, J. (1997) A world of their own making: A history of myth and ritual in family life Oxford University 
Press, Oxford.

HANSEN, K. (2005) Not-so-Nuclear Families: Class, Gender and Networks of Care Rutgers University Press.

HOLDSWORTH C. and Morgan D. (2006) Transitions in Context: Leaving Home, Independence \& Adulthood, Polity Press, Cambridge.

IRWIN S. (2004) 'Attitudes Care and Commitment: Patterns and Process' Sociological Research On-Line Sociological Research Online, Volume 9, 3, <http://www.socresonline.org.uk/9/3/9/3/irwin. html>.

IRWIN, S. and Bottero, W. (2000) 'Market returns? Gender and theories of change in employment relations' British Journal of Sociology 51, 261-80.

JACKSON, S. (1993) 'Even Sociologist Fall in love: An Exploration in the Sociology of Emotions Sociology, 27, 201-220.

JAMIESON, L. (1987) 'Theories of family development and the experience of being brought up' Sociology 21, 591-607

JAMIESON, L. (1998) Intimacy: Personal relationships in modern societies Polity Press, Cambridge.

JAMIESON, L. 'Intimacy transformed: a critical look at the pure relationship' Sociology, 33, 477-494.

JERROME, Dorothy, 1992. Good Company: An anthropological study of old people in groups. Edinburgh University Press, Edinburgh.

LESTHAEGHE, R. (1998) 'On theory development: applications to the study of family formation' Population and Development Review 24, 1-14

LESTHAEGHE, R and Surkyn, J. (2004) 'Value Orientations and the Second Demographic Transition (SDT) in Northern, Western and Southern Europe: An Update.' Demographic Research, 3: 45-86.

MASON, J. (2006) 'Mixing methods in a qualitatively driven way' Qualitiative Research 6, 9-25.

MORGAN, D. (1985) The Family, Politics and Social Theory Routledge \& Kegan Paul, London.

MORGAN, D. (1991) 'Ideologies of marriage and family life' in Clark, D. (ed.) Marriage, Domestic Life and Social Change: Writings for Jacqueline Burgoyne (1944-88). Routledge, London.

MORGAN, David, (1992) 'Marriage and society', in Lewis, Jane, Clark, David and Morgan, David, Whom God Hath Joined Together: The Work of Marriage Guidance. Tavistock and Routledge, London.

MORGAN, D.H. J (1996) Family Connections: An Introduction to Family Studies X Polity, Cambridge.

MORGAN, D. (1999) 'Risk and family practices: accounting for change and fluidity in family life' in E. B. Silva and C. Smart (eds.) The New Family? Sage, London,13-30.

MORGAN, D. (2002) 'Sociological perspectives on the family' in A. Carling, S. Duncan and R. Edwards (eds.) Analysing Families: Morality and rationality in policy and practice London, Routledge.

PAHL, R. E. and Spencer, L. (2004) 'Personal Communities: not simply families of 'fate' or 'choice". Current Sociology, 52,199-221.

PAHL, Ray (2000) On Friendship Polity, Cambridge.

PHILLIPSON, C., Bernard, M., Phillips, J. and Ogg, J. (2001) The Family and Community Life of Older People: Social Networks and Social Support in Three Urban Areas Routledge, London.

PLUMMER K.(2003) Intimate Citizenship: Private Decisions and Public Dialogues Washington University Press.

RAMAZANOGLU, C. with Holland, J. (2002) Feminist Methodology: Challenges and Choices Sage, London.

ROSE, N. (1996) Inventing Our Selves: Psychology, Power and Personhood Cambridge University Press.

ROSENEIL S. and Budgeon S. (2004) 'Cultures of Intimacy and Care Beyond the Family: Personal Life and Social Change in the Early Twenty-First Century', Current Sociology, 52, 135-159.

SAVAGE, M., Bagnall, G. and Longhurst, B. (2005) Globalization and Belonging. Sage, London.

SKOLNICH (1991) Embattled Paradise: The American Family in an Age of Uncertainty Basic Books, New York.

SMART C. (2005) 'Textures of Family Life: Further Thoughts on Change and Commitment' Journal of Social Policy 541-556. 
SMITH, D. (1999) Writing the social : critique, theory, and investigations University of Toronto Press.

SPENCER, L. and Pahl, R.(2006) Rethinking Friendship: Hidden Solidarities Today Princeton University Press.

TADMOR, N. (2001) Family and Friends in Eighteenth Century England Cambridge Cambridge University Press

TURNER, J. and Stets J. (2005) The Sociology of Emotions Cambridge University Press.

WEEKS, J., Heapy, B. and Donovan, C. (2001) Same Sex Intimacies: Families of Choice and Other Life Experiments London: Routledge.

WENGER, GC (2001) 'Myths and realities of ageing in rural Britain' Ageing and society 21. 